\title{
Deletion analysis of BMI1 oncoprotein identifies its negative regulatory domain
}

\author{
Ajay K Yadav ${ }^{+1,2}$, Anagh A Sahasrabuddhe ${ }^{+1}$, Manjari Dimri ${ }^{1}$, Prashant V Bommi ${ }^{1}$, Rachana Sainger ${ }^{1,3}$ and \\ Goberdhan P Dimri*1
}

\begin{abstract}
Background: The polycomb group (PCG) protein BMI1 is an important regulator of development. Additionally, aberrant expression of BMI1 has been linked to cancer stem cell phenotype and oncogenesis. In particular, its overexpression has been found in several human malignancies including breast cancer. Despite its established role in stem cell maintenance, cancer and development, at present not much is known about the functional domains of BMI1 oncoprotein. In the present study, we carried out a deletion analysis of BMI1 to identify its negative regulatory domain.

Results: We report that deletion of the C-terminal domain of BMI1, which is rich in proline-serine (PS) residues and previously described as PEST-like domain, increased the stability of BMI1, and promoted its pro-oncogenic activities in human mammary epithelial cells (HMECs). Specifically, overexpression of a PS region deleted mutant of BMI1 increased proliferation of HMECs and promoted an epithelial-mesenchymal transition (EMT) phenotype in the HMECs. Furthermore, when compared to the wild type BMI1, exogenous expression of the mutant BMI1 led to a significant downregulation of p16INK4a and an efficient bypass of cellular senescence in human diploid fibroblasts.

Conclusions: In summary, our data suggest that the PS domain of BMI1 is involved in its stability and that it negatively regulates function of BMI1 oncoprotein. Our results also suggest that the PS domain of BMI1 could be targeted for the treatment of proliferative disorders such as cancer and aging.
\end{abstract}

\section{Background}

Polycomb Group (PcG) proteins originally discovered in Drosophila are evolutionarily conserved epigenetic regulators of development [1-3]. These proteins regulate proliferation and differentiation of cells via epigenetic silencing of important growth regulatory genes $[3,4]$. The first mammalian PcG gene BMI1 (B lymphoma Mo-MLV insertion region 1) was identified as a c-myc cooperating oncogene using an $\mathrm{E} \mu$-myc transgenic mouse model $[5,6]$. There is increasing evidence that the deregulated expression of BMI1 contributes to cancer development. It is overexpressed in a number of cancers, such as mantle cell lymphoma [7], B-cell non-Hodgkin's lymphoma [8], myeloid leukemia [9], non-small cell lung cancer [10], colorectal cancer [11], breast and prostate cancers $[12,13]$, and head and neck cancers $[14,15]$. In addition to

\footnotetext{
*Correspondence: gdimri@northshore.org

1 Department of Medicine, NorthShore University HealthSystem Research Institute, Evanston, IL 60201, USA

+ Contributed equally

Full list of author information is available at the end of the article
}

its role in cancer, BMI1 is also known to be required for self-renewal of neural, hematopoietic, intestinal and mammary stem cells [16-21]. Consistent with its role in stem cell self-renewal, BMI1 expression is thought to promote stem-ness in tumor cells [12,22], and BMI1 is considered an important marker of breast cancer stem cells [23]. Recent mouse xenograft studies using BMI1 and Ras co-overexpressing human mammary epithelial cells (HMECs) also support oncogenic roles for BMI1 in breast cancer development and metastasis of breast cancer cells $[24,25]$.

PcG proteins assemble into polycomb repressive complexes (PRCs), which possess histone posttranslational modification (PTM) activities and act in a sequential fashion to mediate gene silencing [3]. Biochemically, BMI1 is a core component of PRC1, which ubiquitinates histone $2 \mathrm{~A}$ at lysine 119 residue [26], and acts downstream of PRC2, which trimethylates lysine 27 residue of histone $3[27,28]$. Although BMI1 is a prominent component of PRC1, its exact role in PRC1 is unclear. BMI1 by itself does not appear to have an E3 ubiquitin ligase activ- 
ity [29], instead, the E3 ubiquitin ligase activity of PRC1 strictly depends on Ring1B (RING2) protein. However, it has been shown that Ring1B-mediated E3 ubiquitin ligase activity of PRC1 complex is enhanced by BMI1 [29-31].

Structurally, human BMI1 is comprised of 326 amino acids [32]. The primary structure of BMI1 in mice revealed the presence of a RING finger (RF) domain at the N-terminus, a potential HTH (helix turn helix) domain in the middle and a PEST (proline (P), glutamic acid $(\mathrm{E})$, serine $(\mathrm{S})$ and threonine $(\mathrm{T})$ rich) -like domain at the C-terminus [5,6]. These domains of BMI1 are highly conserved across mammalian species including human. The BMI1 also contains two putative nuclear localization signals (NLS), NLS1 (KRRR, amino acid residues 92-95) and NLS2 (KRMK, amino acid residues 232-235). Of these two, only NLS2 appears to be functional in targeting BMI1 to the nucleus in mouse and human cells $[33,34]$. We have previously carried out functional analysis of BMI1 and shown that the RING finger and HTH domains of BMI1 are required for downregulation of p16INK4a tumor suppressor and bypass of senescence in human diploid fibroblasts (HDFs) [35]. We also showed that both of these domains are required for immortalization of normal HMECs [34].

PEST-like domains rich in proline (P), glutamic acid $(\mathrm{E})$, serine $(\mathrm{S})$ and threonine $(\mathrm{T})$ residues have been described in the literature [36]. Although the actual contribution of such domains to protein turn-over is not clear and such sequences may not mediate proteolysis per se, the PEST-like domains are present in many proteins that undergo rapid turn-over such as cyclins, NF- $\mathrm{k} \beta$, cMyc, c-Fos, ODC, ABCA1 etc [36-44]. Since a PEST-like domain, which is rich in proline $(\mathrm{P})$ and serine $(\mathrm{S})$ residues is present in BMI1 $[5,6]$, and at present very little is known about its functional role, we carried out a structural-functional analysis of BMI1 to define the role of this domain in BMI1. As the PEST-like domain in BMI1 is not rich in $\mathrm{E}$ - and $\mathrm{T}$ - residues, here in, we refer this domain as the PS domain. Our data indicate that the PS domain of BMI1 may indeed regulate its proteolysis and that it may function as a negative regulatory domain of BMI1.

\section{Results}

\section{Deletion of the PS domain results in increased half life of BMI1}

We have previously reported that the RING finger and $\mathrm{HTH}$ domains of BMI1 are required for its pro-proliferative activities and to enable bypass of senescence in HDFs and HMECs $[34,35]$. To further understand the role of the various domains of BMI1, we generated a PS deletion mutant which we termed as $\triangle \mathrm{PS}$ mutant (Fig. 1A), and used it as a tool to study the biochemical and posttranslational regulation of BMI1. MCF10A cells stably expressing wild type (WT), and $\triangle \mathrm{RF}, \Delta \mathrm{HT}$ and $\triangle \mathrm{PS}$ mutants of
BMI1 were selected in puromycin as described in the Materials and Methods section. The drug-selected cells were further passaged in culture and the half lives of wild type and mutant BMI1 proteins were determined using cyclohexamide $(\mathrm{CHX})$ treatment at different time points. Our results indicated that the wild type BMI1 has a half life of $\sim 25$ minutes and that the $\Delta R F$, and $\Delta H T$ mutants degraded faster than the wild type BMI1 with a half life of 15-20 minutes (Fig. 1B). On the other hand, $\triangle \mathrm{PS}$ mutant of BMI1 was relatively very stable and did not undergo any significant proteolysis up to 60 minutes (Fig. 1B).

To determine the half life of the $\triangle \mathrm{PS}$ mutant of BMI1, MCF10A-BMI1WT and MCF10A-BMI1 $\triangle$ PS cells were further treated with $\mathrm{CHX}$ for longer periods (0-240 min) and the half lives of the wild type BMI1 and $\triangle \mathrm{PS}$ mutant were determined as described above. Our results indicated that the half life of $\triangle \mathrm{PS}$ mutant of BMI1 is about $120 \mathrm{~min}$ (Fig. 2A). We also determined the rate of proteolysis of endogenous BMI1 in MCF10A-BMI1 $\triangle$ PS cells. Our analysis of the half life of BMI1 proteins indicated that, similar to the overexpressed wild type BMI1, the endogenous BMI1 also has a half life of 25-30 min in MCF10A cells (Fig. 2A lower panel).

During our analysis of BMI1 half life, we noticed that the wild type but not the $\triangle \mathrm{PS}$ mutant of BMI1 is detected as multiple bands of different mobility, and that the intensity of the slow mobility bands increases with CHX treatment. To determine whether the slow mobility bands represent phosphorylated forms of BMI1, we treated total cell extract of MCF10A-BMI1 cells with calf intestinal alkaline phosphatase (CIP) and performed an immunoblot analysis (IB) of BMI1. Our results indicated that the slower mobility bands of BMI1 likely do represent phosphorylated forms of BMI1, which disappear upon CIP treatment (Additional file 1, Fig. S1A).

To further confirm the relatively stable nature of the $\triangle \mathrm{PS}$ mutant of BMI1, we treated MCF10A-BMI1WT and MCF10A-BMI1 $\mathrm{PS}$ cells with a proteosome inhibitor MG132 at different time points. We reasoned that if the $\triangle \mathrm{PS}$ mutant is more stable than the wild type BMI1 and is not degraded as fast as the wild type, it will not accumulate upon MG132 treatment, which is a commonly used to inhibit $26 \mathrm{~S}$ proteosome. Indeed, our results indicated that the wild type BMI1 is accumulated within $30 \mathrm{~min}$ upon MG132-treatment, while the $\triangle \mathrm{PS}$ mutant of BMI1 had not accumulated after 30 min of treatment (Fig. 2B). Our data also indicated that longer treatment of MG132 results in accumulation of $\triangle \mathrm{PS}$ mutant of BMI1; however, compared to the wild type, the relative accumulation of $\triangle \mathrm{PS}$ mutant of BMI1 was much less pronounced at all the time points we analyzed (Fig. 2B).

To determine whether BMI1 is non-specifically degraded by proteases, we treated cells with two commonly used protease inhibitors; phenylmethylsulfonyl 


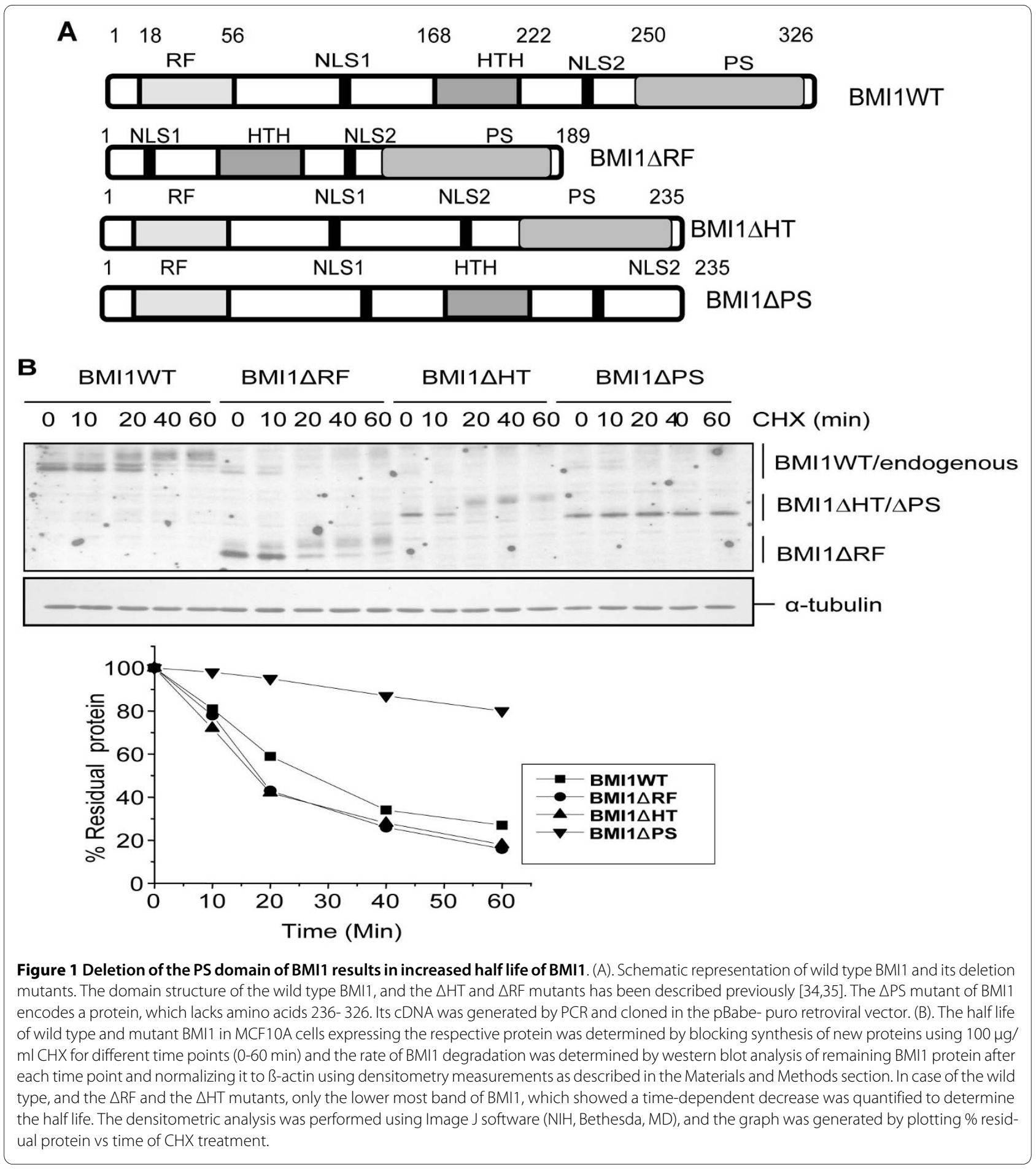

fluoride (PMSF) and aprotinin. We also used lactacystin, another specific inhibitor of 26S-proteosome. After treatment of the cells with PMSF, aprotinin and lactacystin, BMI1 was detected by IB analysis. Our results indicated that BMI1 is accumulated only in lactacystin-treated cells (Additional file 1, Fig. S1B). Thus, BMI1 is specifically degraded by a $26 \mathrm{~S}$ proteosome-mediated protein degra- dation pathway. Finally, we also determined the half life of wild type BMI1 and $\triangle$ PS mutants in HDFs. The results indicate that similar to what we saw in MCF10A cells, the wild type BMI1 has a half life of 25 min in MRC5 and IMR90 strains of HDFs, while the $\triangle \mathrm{PS}$ mutant of BMI1 is very stable in these cells (Additional file 1, Fig. S2 and Fig. S3). Collectively, our data suggest that deletion of the PS 


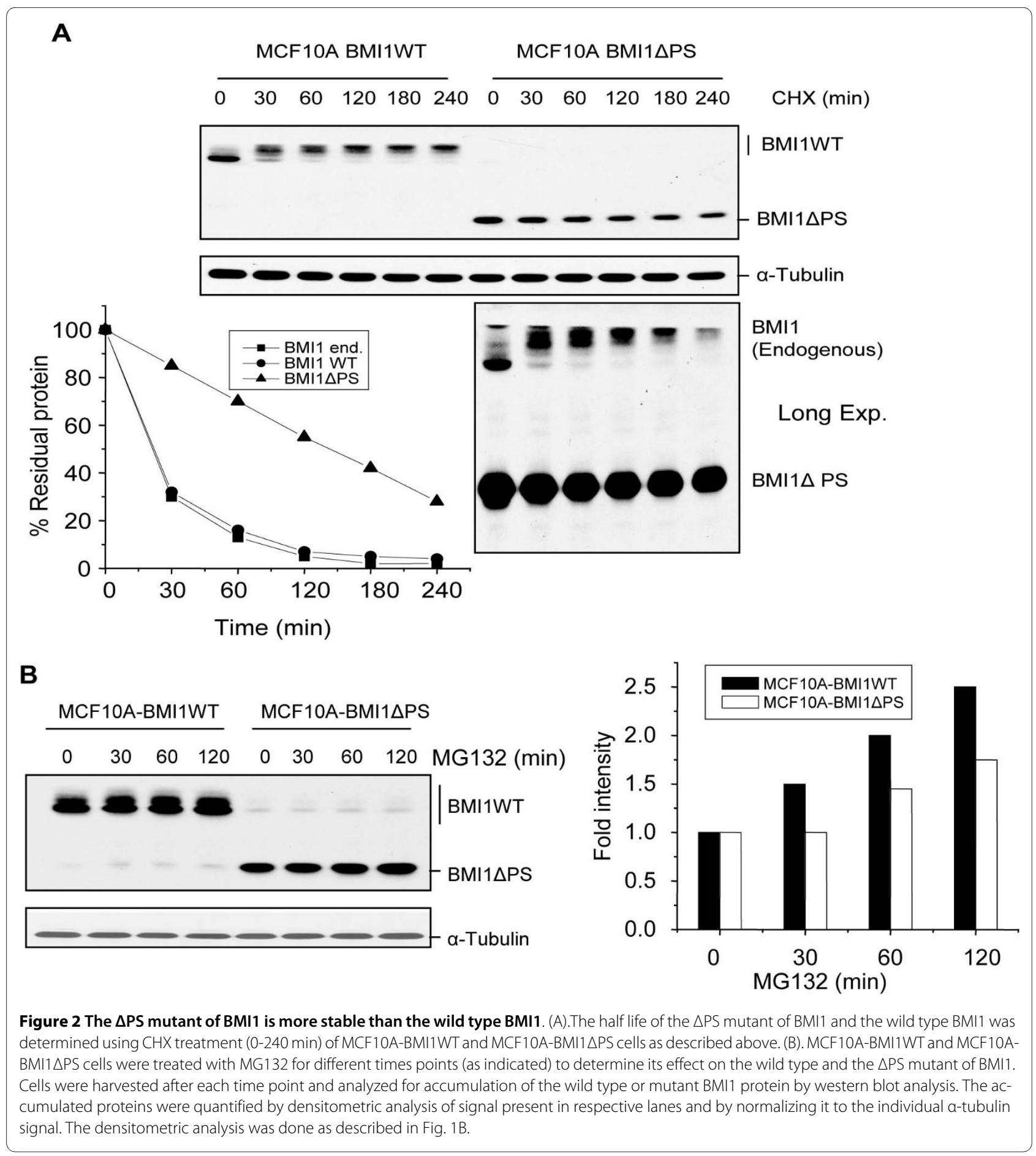

domain of BMI1 renders it much more stable compared to the overexpressed or endogenous wild type BMI1.

\section{Deletion of the PS domain of BMI1 promotes proliferation of cells}

To determine the possible consequences of deleting the PS region of BMI1 on PRC1 activity, we examined the levels of H2A K119Ub in MCF10A-B0 control, MCF10A-
BMI1WT and MCF10A-BMI1 $\triangle$ PS cells. Our results indicated that the wild type BMI1 increased the levels of $\mathrm{H} 2 \mathrm{~A}$ K119Ub and that deletion of the PS region resulted in further increase in H2A K119Ub levels (Fig. 3A). These data suggest that the $\triangle \mathrm{PS}$ mutant of BMI1 may be physiologically more active. Previously, we reported that the overexpression of BMI1 in normal and immortal cells results in increased proliferation $[24,25,34,35]$. To deter- 

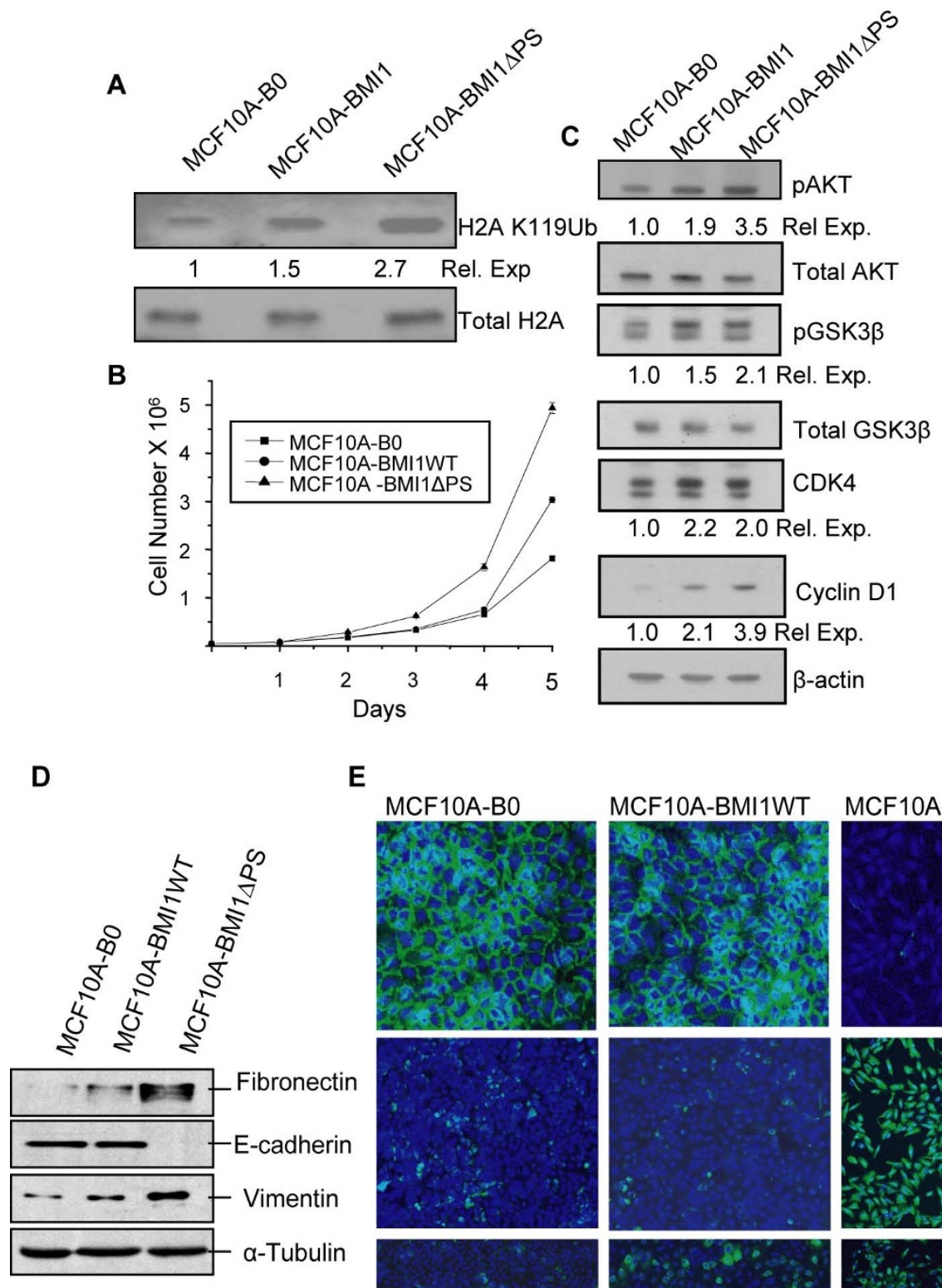

MCF10A-B0
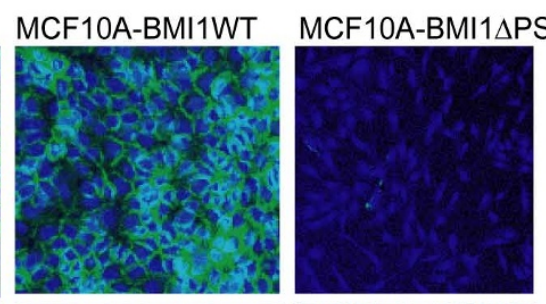

E-cadherin/DAPI
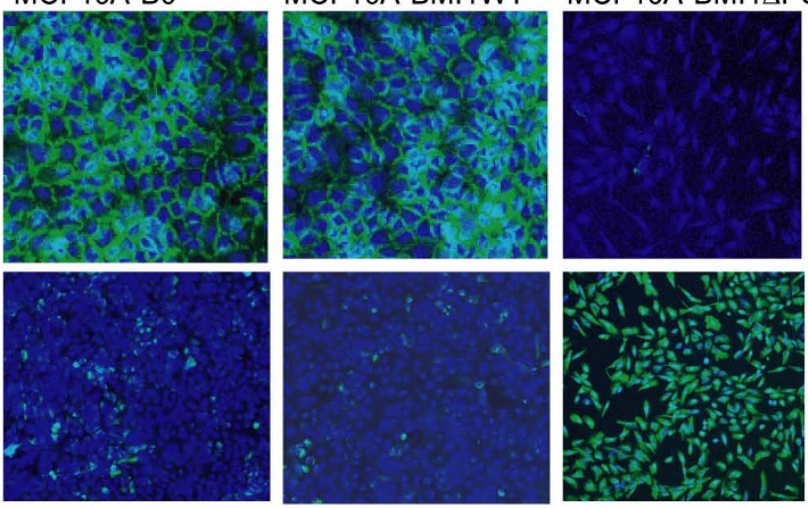

Vimentin/DAPI
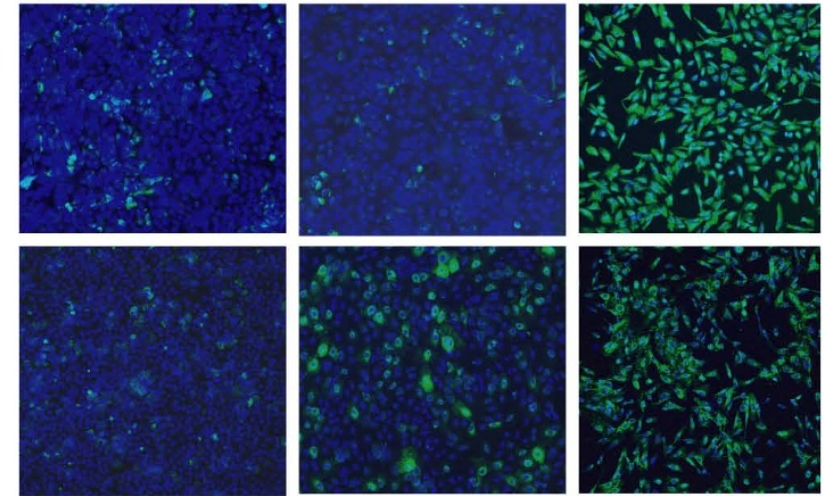

Fibronectin/DAPI

Figure 3 Deletion of the PS domain of BMI1 augments its pro-proliferative activity and promotes EMT in MCF10A cells. (A). Wild type BMI1 and $\triangle P S$ mutant of BMI1 upregulates H2A K1 19Ub activity of PRC1. The relative expression of H2A K119Ub in MCF10A control, MCF10A-BMI1WT and MCF10A-BMI1 $\triangle$ PS cells was determined by western blot analysis and densitometry as described in the Materials and Methods section and Fig. 1B. (B). MCF10A-derived cells expressing wild type and mutant BMI1 were plated in P100 plastic dishes $\left(5 \times 10^{5} /\right.$ plate). Cells were harvested at the indicated day (days 1-5) and counted using a hemocytometer. Proliferation curves were generated by plotting the number of cells against number of days. (C). Increase in AKT activity (phospho-AKT and phospho-GSK3 $\beta$ ), and the expression of AKT/GSK3 $\beta$ targets cyclin D1 and CDK4 was determined by western blot analysis using antibody specific to each protein as described in the Materials and Methods section. $\beta$-actin was used as a loading control. The relative expression of phospho-AKT (normalized to total AKT), Phospho-GSK3 $\beta$ (normalized to total GSK3 $\beta$ ), CDK4 (normalized to $\beta$-actin) and cyclin D1 (normalized to $\beta$-actin) was quantified by densitometry as described in Fig. 1B. (D). MCF10A-derived cells expressing wild type BMI1 or the $\triangle P S$ mutant were analyzed for the expression of E-cadherin, fibronectin and vimentin using western blot analysis. a-tubulin was used as a loading control. (E). The expression of E-cadherin, vimentin and fibronectin in control, and wild type BMI1- and $\triangle P S$ mutant-overexpressing cells was determined by immunostaining as described in the Materials and Methods section. After immunostaining, cells were photographed (10X) using a Nikon Eclipse 80i confocal microscope. 
mine whether deletion of the PS region further promotes proliferation, we examined the rate of proliferation of MCF10A-B0 control, MCF10A-BMI1WT and MCF10A$\mathrm{BMI} 1 \triangle \mathrm{PS}$ cells. Our data indeed indicated that MCF10A cells expressing the $\triangle \mathrm{PS}$ mutant proliferated at a higher rate than the MCF10A-B0 control and MCF10ABMI1WT cells (Fig. 3B). We also previously reported that BMI1 upregulates AKT in HMECs [45]. Hence, we further examined expression of AKT, GSK3 $\beta$, cyclin D1 and CDK4 in cells overexpressing the $\triangle \mathrm{PS}$ mutant of BMI1 and compared it with cells overexpressing the wild type BMI1. The results of western blot analysis suggested that while overexpression of the wild type BMI1 results in modest upregulation of AKT activity (Phospho-AKT) and cyclin D1, the $\triangle \mathrm{PS}$ mutant further augmented upregulation of AKT and cyclin D1 (Fig. 3C). As compared to overexpression of the wild type (WT) BMI1, no further upregulation of CDK4 was noticed upon overexpression of the $\triangle \mathrm{PS}$ mutant. As a downstream phosphorylation target of AKT, increased phosphorylation of GSK3 $\beta$ was also evident in cells overexpressing $\triangle \mathrm{PS}$ mutant of BMI1 (Fig. 3C). No appreciable changes were noticed in the expression of total AKT and total GSK3 $\beta$ (Fig. 3C). Thus, deletion of the PS region of BMI1 further augments the proliferative activity of BMI1.

\section{Overexpression of the $\triangle \mathrm{PS}$ mutant of BMI1 results in a partially transformed phenotype in HMECs}

Because the $\triangle \mathrm{PS}$ mutant of BMI1 is more stable and more pro-proliferative, we examined whether its overexpression can transform MCF10A cells. MCF10A cells overexpressing the wild type BMI1 or the $\triangle \mathrm{PS}$ mutant were seeded in soft agar and examined for colony formation over two weeks. The results indicated that neither overexpression of the wild type BMI1 nor the $\triangle \mathrm{PS}$ mutant is sufficient to transform MCF10A cells (not shown). Similarly, overexpression of neither the wild type nor the mutant BMI1 was sufficient to form foci in 3T3 fibroblasts (not shown).

The morphology of MCF10A-BMI1 $\triangle \mathrm{PS}$ cells appeared to be more fibroblastic than that of the control or the wild type BMI1 overexpressing cells (Additional file 1, Fig. S4). The fibroblastic morphological changes in epithelial cells are suggestive of an EMT phenotype; hence, we analyzed MCF10A-B0, MCF10A-BMI1WT and MCF10ABMI1 $\triangle \mathrm{PS}$ cells for the presence of EMT markers by immunostaining and western blot analysis (Fig. 3D \&3E). The results indicated that the MCF10A-B0 control and MCF10A-BMI1 cells expressed E-cadherin, a cell-cell junction protein characteristic of epithelial cells, while MCF10A-BMI1 $\triangle \mathrm{PS}$ cells lost the expression of E-cadherin (Fig. 3D \&3E). In addition, MCF10A- BMI1 $\triangle \mathrm{PS}$ cells also expressed fibroblastic markers such as vimentin and fibronectin (Fig. 3D \&3E). These data indicate that the expression of a stable mutant of BMI1 which contains a deletion of the PS domain can induce an EMT phenotype in HMECs. Extensive passaging of the wild type BMI1 expressing cells, particularly at passages more than 15 after drug selection, also exhibited partial EMT and loss of E-cadherin expression (not shown). Since extensive passaging of cells in culture can result in the accumulation of additional stochastic lesions, it is possible that such lesions cooperate with the wild type BMI1 to inhibit E-cadherin expression and induce a partial EMT phenotype.

Next, we performed invasion and wound healing assays to determine the migratory potential of control and MCF10A cells overexpressing either the wild type BMI1 or the $\triangle \mathrm{PS}$ mutant. The results indicated that MCF10ABMI1 $\triangle \mathrm{PS}$ cells are highly invasive compared to control cells, while MCF10A-BMI1 exhibited a modest invasive potential (Fig. 4A). Similarly, the results of the wound healing assay suggest that the wild type BMI1 expressing cells only exhibit a minimal migration, while MCF10ABMI1 $\triangle \mathrm{PS}$ cells possess the highest migration potential and that these cells filled the wound quickly compared to the MCF10A-B0 control cells (Fig. 4B). Thus, our data suggest that overexpression of the $\triangle \mathrm{PS}$ mutant of BMI1 leads to acquisition of migration and invasion properties indicative of the partial transformation of HMECs.

To further confirm the partial transformation of HMECs by the $\triangle \mathrm{PS}$ mutant of BMI1, we analyzed cells for 3-D (3-dimensional) growth in Matrigel. Our data indicated that indeed $\triangle \mathrm{PS}$ mutants expressing MCF10A cells are partially transformed (Fig. 5). Specifically, the MCF10A-B0 control cells formed normal round acini, while the wild type BMI1 expressing MCF10A cells formed slightly irregular acini, and the $\triangle \mathrm{PS}$ mutant expressing MCF10A cells formed a highly branched structure (Fig. 5A). Next, we performed E-cadherin and $\alpha 6$ integrin immunostaining together with Topro-3 nuclear staining of the acini. The results showed that MCF10A-B0 cells form normal acini with a proper lumen; MCF10-BMI1 cells form irregular acini filled with cells, while there is no lumen-like structure present at all in the $\triangle \mathrm{PS}$ mutant expressing MCF10A cells (Fig. 5B). Furthermore, the MCF10A-BMI1 $\triangle$ PS cells were devoid of E-cadherin and $\alpha 6$ integrin confirming induction of EMT and a partially transformed phenotype in these cells (Fig. 5).

\section{Overexpression of the $\triangle P S$ mutant of BMI1 results in bypass of senescence in HDFs}

Since MCF10A cells are immortal and do not undergo replicative senescence, we used HDFs for examining the effect of overexpression of the $\triangle \mathrm{PS}$ mutant on senescence. WI-38 cells stably expressing the wild type BMI1 or the PS mutant of BMI1 were generated as described in 


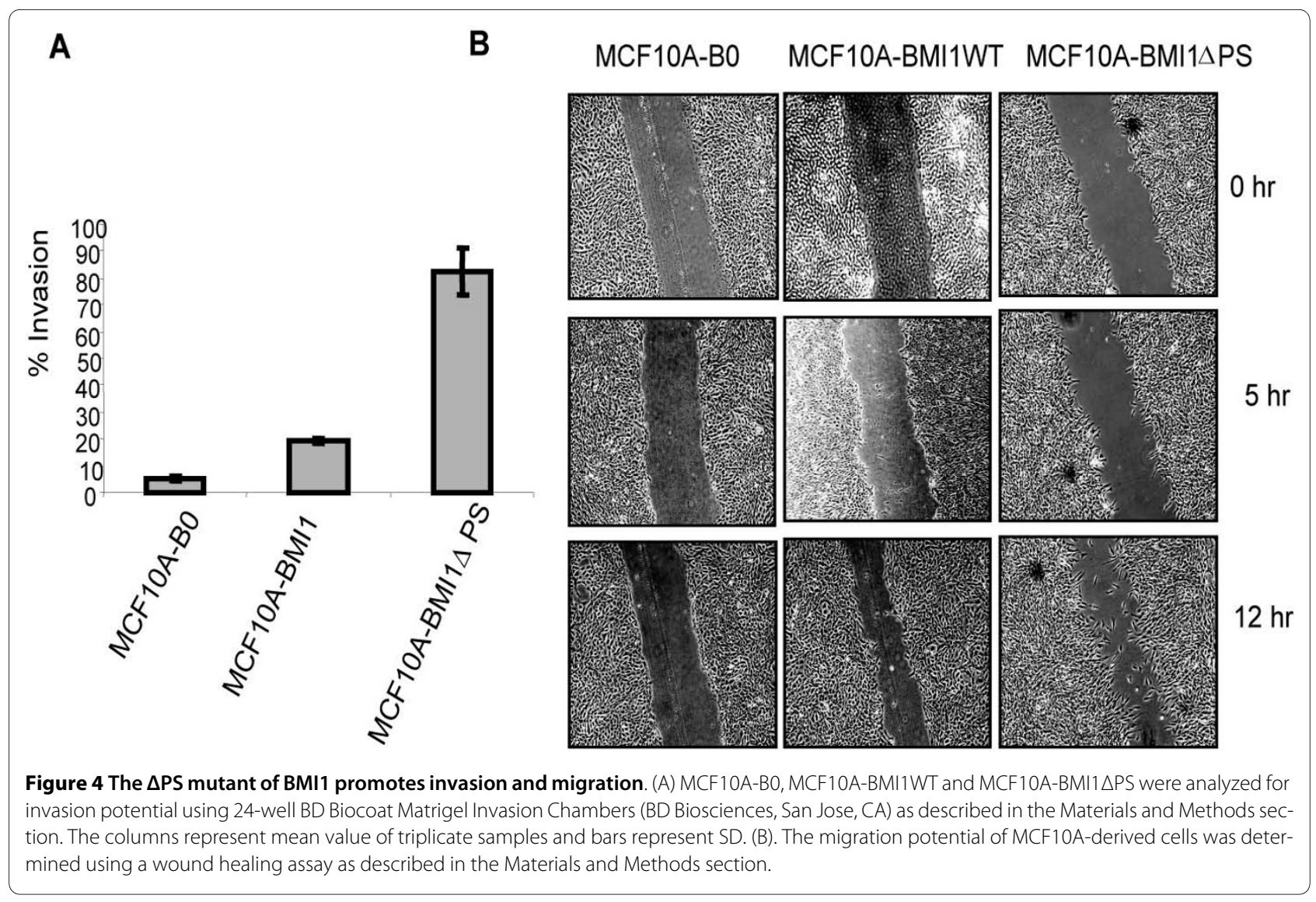

the Materials and Methods section. After selection and culturing for an additional passage, WI-38-derived cells were analyzed for proliferation and bypass of senescence. Results of proliferation assays carried over 4 days indicated that WI-38 cells expressing $\triangle \mathrm{PS}$ mutant proliferated at a faster rate compared to the wild type BMI1 expressing cells, which proliferated better than WI-38-B0 control cells (Fig. 6A). We also performed long-term proliferation assays of mid passage WI-38 cells expressing the wild type BMI1 or the $\triangle \mathrm{PS}$ mutant. The cells were continually passaged in culture and the cumulative cell numbers at each passage were determined to derive a long-term growth/proliferation curve. The results indicated that the WI-38 cells expressing $\triangle$ PS mutant proliferated for more than 50 days before undergoing senescence, while the control B0 and wild type BMI1expressing cells underwent senescence within 15 days and 25 days of growth after selection respectively (Fig. $6 \mathrm{~B})$.

Since BMI1 is known to downregulate p16INK4a in HDFs, we analyzed WI-38-B0, WI-38-BMI1WT and WI38-BMI1PS cells for the expression of p16INK4a. Our data indicated that, as expected, overexpression of the wild type BMI1 led to downregulation of p16INK4a. Importantly, WI-38-BMI1 $\triangle$ PS cells exhibited even fur- ther downregulation of p16INK4a (Fig. 6C). Significant downregulation of p16INK4a by the $\triangle \mathrm{PS}$ mutant was also noticed in hTERT-immortalized WI-38 cells (Additional file 1, Fig. S5). Because p16INK4a regulates senescence and BMI1 downregulates p16INK4a, cells expressing the wild type BMI1 or the $\triangle \mathrm{PS}$ mutant, and control WI-38B0 cells were analyzed at the same passage number after puromycin selection for the induction of spontaneous senescence using SA- $\beta$-gal marker [46]. Consistent with our earlier data [35], overexpression of BMI1 resulted in significantly fewer senescent cells when compared to control B0 cells (Fig. 6D). Importantly, overexpression of the $\triangle \mathrm{PS}$ mutant of BMI1 further decreased the number of senescent cells indicating more efficient bypass of senescence in HDFs (Fig. 6B, D). Thus our data indicate that the $\triangle \mathrm{PS}$ mutant of BMI1 is physiologically more active and pro-proliferative as compared to the wild type BMI1. With respect to proliferation and senescence, similar results were obtained in MRC5, which is another commonly used strain of HDFs (Additional file 1, Fig. S6).

\section{Discussion}

The mouse Bmi1 gene was cloned by two different groups in 1991 [5,6], and shortly after that, the human homologue of mouse Bmi1 was cloned [32]. Since then most of 


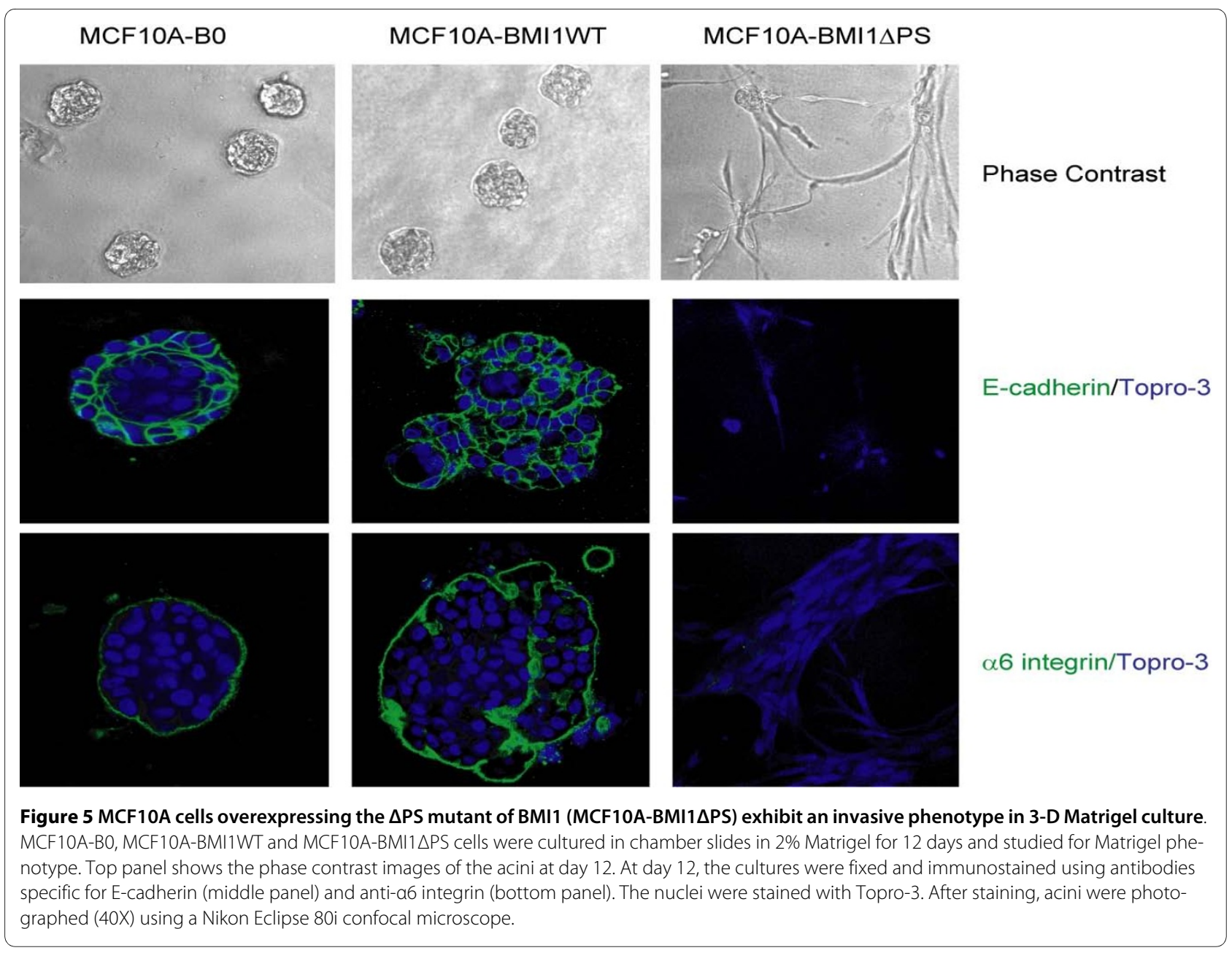

the studies on BMI1 have been focused on its role in oncogenesis and stem cell phenotype, and very few studies have analyzed the regulation of BMI1. Only recently, we and others analyzed the transcriptional regulation of BMI1 [47,48]. At present, virtually nothing is known about additional transcriptional or posttranslational regulation of BMI1. Such regulation of BMI1 is likely to be highly relevant for the role of BMI1 in development and pathobiology of various diseases, including cancer.

The initial characterization of mouse and human BMI1 predicted the presence of three structural domains in BMI1; a RING finger domain, an HTH domain and a potential PEST domain. Except for the RING finger domain, the functional role of these domains is largely undefined. The RING finger domain is most recognizable domain in BMI1. Although such domains are found in E3 ubiquitin ligases, BMI1 by itself lacks E3 ubiquitin ligase activity. Nonetheless, this domain has been shown to be functionally important $[15,34,35,49]$.

A RING finger domain mutant of Bmi1 (the mouse homologue of human BMI1) was shown to be ineffective in collaborating with c-myc to induce B- and T- cell lym- phomas [49]. Moreover, the deletion of the RING finger domain of BMI1 may lead to dominant negative activity of the mutant BMI1 [35], as the overexpression of the $\triangle \mathrm{RF}$ mutant of BMI1 induces p16INK4a expression and premature senescence, whereas the expression of the wild type BMI1 suppresses p16INK4a expression and bypasses senescence in HDFs [35]. Alkema et al. also showed that in addition to the RING finger domain, a centrally located HTH domain of Bmil was also required for B- and T- cell lymphomagenesis by Bmi1 and c-myc [49]. Interestingly, the PS region of Bmil was not required to induce B- and $\mathrm{T}$ - cell lymphomas in the mouse model [49]. Thus, at present, it is not clear what role the PS domain of BMI1 plays in oncogenesis.

In the present study, we report that deletion of the PS domain of BMI1 increases its half life and that the mutant protein becomes very stable. Although naturally occurring deletions in the PS region of BMI1 have not been reported, our studies form the basis of detailed analysis of posttranslational regulation of BMI1 and biochemical analysis of its degradation pathways. With respect to biochemical analysis of BMI1 proteolysis, we noticed the 
A

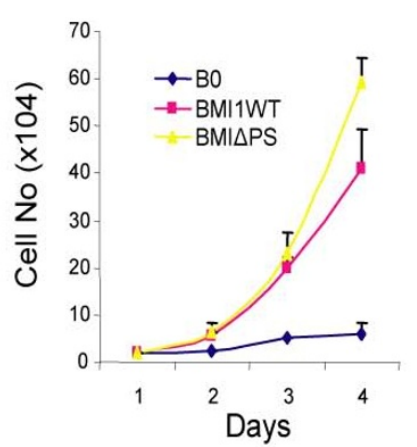

B

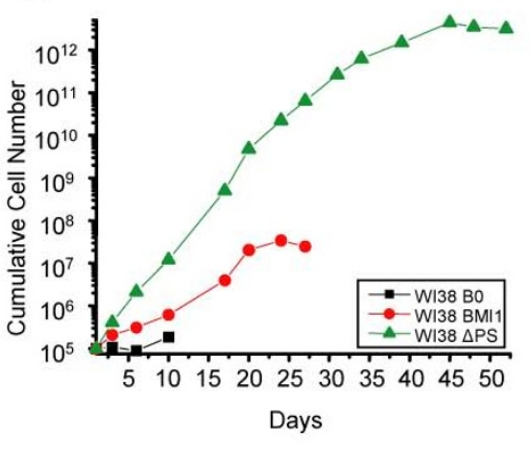

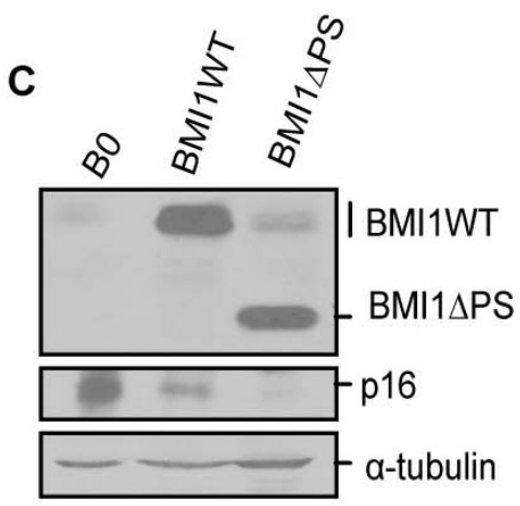

D
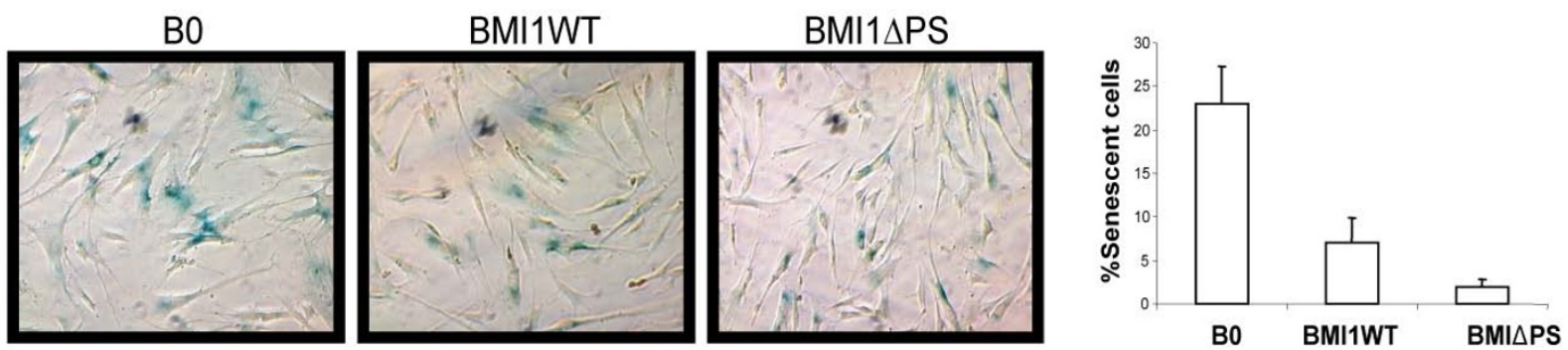

Figure 6 The $\triangle \mathrm{PS}$ mutant of BMI1 promotes proliferation and bypasses senescence more efficiently than the wild type BMI1 in HDFs. (A). WI-38 cells expressing wild type BMI 1 or $\triangle \mathrm{PS}$ mutant of BMI1, and control WI-38-B0 cells were plated at $1 \times 10^{4}$ cells/well in multi well plates, and harvested and counted after indicated number of days. Proliferation curves were generated by plotting the number of cells against the number of days. (B). Mid passage control BO, and wild type BMI1-and $\triangle P S$ mutant-expressing cells were generated and serially passaged in culture to determine the effect of the mutant BMI1 on the long term replicative life span of WI-38 cells. After selection, at each passage $10^{5}$ cells were passaged in a T25 and cultures were grown until 70-80\% confluence. At each passage, cell numbers were counted and the proliferation curve was generated by plotting cumulative cell number vs days. (C). WI-38-derived cells were analyzed for the expression of p16INK4a, BMI1 (wild type and mutant), and a-tubulin (loading control) by western blot analysis as described in the Materials and Methods section. (D). The number of senescent cells in WI-38-B0, WI-38BMI1 WT and WI-38-BMI1 $\triangle$ PS culture at passage 3 (after selection) was determined using SA- $\beta$-gal staining as described in the Materials and Methods section. After staining, the cells were photographed (10X) under phase contrast using a light microscope. The number of senescent cells and total number of cells in each culture were counted in multiple fields to determine the percentage of senescent cells.

presence of a degron motif DSG $(\mathrm{X})_{2+\mathrm{n}} \mathrm{S}$, in the PS domain of BMI1. The degron motif is a recognition site for the $\beta$ TRCP ( $\beta$-transducin repeat containing protein), which is a member of the F-box protein family and constitutes one of the subunit of the ubiquitin ligase complex known as SCF (SKP-Cullin-F-Box) [50]. The SCF complex is involved in proteosome-mediated degradation of several proteins known to be involved in cell cycle and oncogenesis such as CDC25A [51-53], Gli [54,55] Mcl-1 [56], and PDCD4 [57]. It is tempting to speculate that a $\beta$ TRCPbased SCF complex posttranslationally regulates the stability of BMI1. Identification and detailed characterization of such an SCF complex and its constituents remain to be undertaken.

We reasoned that if the deletion of the PS region makes BMI1 more stable, overexpression of the $\triangle \mathrm{PS}$ mutant of BMI1 may augment known biological activities of the wild type protein and/or exhibit additional biological activities. The best known biological activity of BMI1 is regulation of proliferation, which it upregulates via p16INK4a-dependent and -independent pathways. The p16INK4a-independent pathway includes AKT and its targets, and possibly other growth regulatory genes. Indeed, our results indicate that deletion of the PS domain of BMI1 results in augmentation of pro-proliferative activity of BMI1 via both p16INK4a-dependent and independent pathways in different cell types. Specifically, overexpression of the $\triangle \mathrm{PS}$ mutant in HMECs results in upregulation of AKT and its targets such as cyclin D1, and increased proliferation. On the other hand in primary HDFs, which express p16INK4a, overexpression of the $\triangle$ PS mutant results in significant downregulation of p16INK4a accompanied by increase in proliferation and decrease in senescence.

Apart from the increase in proliferation in both epithelial cells and fibroblasts, overexpression of the $\triangle \mathrm{PS}$ mutant also results in induction of an EMT phenotype, which is often accompanied by downregulation of E-cad- 
herin and upregulation of fibroblastic markers such as fibronectin and vimentin. The EMT phenotype is thought to be important not only for development of an organism but also for certain pathological conditions such as cancer and organ fibrosis [58]. PcG proteins, in particular EZH2 has been shown to downregulate E-cadherin in breast and prostate cancer cells $[59,60]$. In addition, a recent report suggests that BMI1 can downregulate E-cadherin expression and induce EMT via downregulation of PTEN in nasopharyngeal epithelial cells (NEPC) [61]. However, our unpublished data suggests that in HMECs, overexpression of the wild type BMI1 is not sufficient to downregulate PTEN. It is possible that unidentified potential pro-oncogenic lesions in immortalized NEPC and nasopharengeal carcinoma cooperate with the wild type BMI1 to downregulate PTEN expression and induce EMT. A different recent report suggests that BMI1 interacts with nuclear PTEN [62]. Interaction of BMI1 with PTEN may also inhibit its function, and this interaction in part could induce an EMT phenotype. Stable BMI1 in the form of the $\triangle \mathrm{PS}$ mutant may also upregulate EZH2, which in turn could directly downregulate the $\mathrm{CDH} 1$ promoter and induce EMT. These hypotheses remain to be examined. In any case, it appears that by increasing BMI1 stability via deletion of its negative regulatory sequences, one can potentially induce EMT; although the mechanism of this induction is not clear at this point.

Although the exact role of the PS domain of BMI1 in the pathobiology of cancer remains to be explored, our studies imply that under certain pathological conditions, BMI1 may be more stable due to deregulation of its degradation machinery, which is likely to be regulated by the sequences present in the PS region of BMI1. So far there is no report of somatic oncogenic mutations or deletions occurring in the PS region of BMI1; however such a possibility cannot be ruled out. In summary, our data implicates the PS domain of BMI1 in its negative regulation, possibly via posttranslational mechanisms. Based on our new and published data, we propose that the RING finger domain of BMI1 can be classified as a catalytic domain, while the PS domain of BMI1 can be termed as a regulatory domain. In view of the well established roles of BMI1 in oncogenesis and stem cell maintenance, our studies have important implications for the pathobiology of cancer and the development of novel treatment strategies for cancer patients.

BMI1 and its target p16INK4a are also important regulators of in vivo aging. Recently it was shown that Bmi1-/mice present several growth defects, progeroid phenotype, such as hair loss, lens cataracts and reduced locomotor activity, and a high lethality rate exceeding 75\% [63]. Furthermore, the levels of p16INK4a , which is a well established target of BMI1, but not other CDK inhibitors increase with aging in vivo, and inhibition of p16INK4a can ameliorate the physiological impact of aging on stem cells and improve injury repair in aged tissues [64-68]. As the deletion of the PS domain of BMI1 results in a stable and constitutively active BMI1, and leads to a robust downregulation of p16INK4a, we speculate that the PS region of BMI1 could also be targeted for the development of treatment strategies for age-related pathologies.

\section{Methods}

Cells, cell culture methods, and senescence and proliferation assays

The MCF10A cell line was obtained from ATCC (Manassas, VA, USA), and cultured as described previously [69]. WI-38 and MRC5 strains of HDFs were obtained from National Institute on Aging (NIA), Aging Cell Repository, Coriell Institute for Medical Research, Camden, NJ. HDFs were passaged in culture in DMEM containing $10 \%$ FCS, $2 \mathrm{mM}$ L-glutamine at $37^{\circ} \mathrm{C}$ under $10 \% \mathrm{CO}_{2}$ and $90 \%$ atmosphere as described $[35,46,47,70]$. The induction or bypass of senescence in HDFs expressing wild type or mutant BMI1 proteins was determined using histochemical staining for senescence-associated beta galactosidase (SA- $\beta$-gal) marker as described $[35,46,47,70]$. Similarly, short and long term proliferation assays were done as described $[35,46,47,70]$.

\section{Retrovirus production, infection and generation of cells expressing wild type or mutant BMI1 proteins}

The cDNA of mutant BMI1 protein lacking the PS domain was generated by PCR and cloned into pBabepuro retroviral vector to generate $\mathrm{pBabe-BMI} 1 \Delta \mathrm{PS}$. The pBabe-BMI1 WT (wild type), pBabe-BMI1 $\Delta$ RF (RING finger deleted) and pBabe-BMI $1 \mathrm{HT}$ (HTH domain deleted) have been described previously [34,35] (Fig. 1A). Retroviruses expressing wild type or mutant BMI1 proteins were produced by transiently transfecting retroviral vectors together with a packaging plasmid $\mathrm{pIK}$ into a packaging cell line tsa54 as described [70]. After $24 \mathrm{hrs}$ of transfection, retrovirus-containing supernatant was collected, filtered, and directly used to infect recipient cells or was stored at $-80^{\circ} \mathrm{C}$ as described [70]. After three sequential infections, recipient cells were passaged in medium containing puromycin $(0.5-1 \mu \mathrm{g} / \mathrm{ml})$ as described $[35,46,47,70]$. The pool populations of drugselected cells were further passaged in culture and analyzed as necessary.

\section{Antibodies and western blot analyses, and protein half life determination}

Most of the antibodies were obtained from commercial sources. These included; anti-BMI1 mAb (monoclonal antibody) 1H6B10G7 from Invitrogen Corporation (Camarillo, CA), anti-E-cadherin mAb and anti-vimentin 
$m A b$ from BD Biosciences (San Jose, CA), anti- $\alpha 6$ integrin $\mathrm{mAb}$ from Chemicon Corporation (now Millipore, Billerica, MA), and $\mathrm{mAb}$ against $\beta$-actin from SigmaAldrich (St. Louis, MO). Additionally, pAbs (polyconal antibodies) against CDK4, phospho-AKT 1/2/3 (Ser473 ), and AKT-1/2/3, and mAbs against $\alpha$-tubulin, E-cadherin, fibronectin, cyclin D1 and p16INK4a were obtained from Santa Cruz Biotechnology (Santa Cruz, CA). Antibodies against Phospho-GSK3 $\beta$ (Ser9) and total GSK3 $\beta$ were obtained from Cell Signaling Technologies (Danvers, MA).

Western blot analyses of total cell extracts from control and wild type or mutant BMI1- expressing cells using various antibodies were performed as described [47]. The half life of wild type and mutant BMI1 protein was determined using cyclohexamide (CHX) treatment of MCF10A cells expressing BMI1 proteins as described [47]. Briefly, sub confluent MCF10A cells expressing wild type or mutant BMI1 proteins were treated with $100 \mu \mathrm{g} /$ $\mathrm{mL}$ CHX for various time points $(0-240 \mathrm{~min})$ to stop the synthesis of new proteins. After the CHX-treatment, cell lysates were prepared and analyzed for the expression of BMI1 and $\alpha$-tubulin. The normalized \% residual BMI1 was plotted against the different time points to determine the rate of proteolysis and the half-life of BMI1. For the analysis of $\mathrm{H} 2 \mathrm{~A} \mathrm{K119Ub,} \mathrm{total} \mathrm{histones} \mathrm{were} \mathrm{prepared}$ using acid extraction method as described [71], and western blot analysis was carried out using a pAb against $\mathrm{H} 2 \mathrm{~A}$ K119Ub (Millipore Inc., Billerica, MA).

\section{Soft agar, invasion, migration and wound healing assays}

Anchorage-independent growth assay using soft agar, and invasion and migration assays were performed as described [24,69]. Briefly, for invasion assays, $2.5 \times 10^{4}$ cells in $0.2 \mathrm{ml}$ medium were added to the top chambers of Matrigel-coated or control wells (BD Biosciences, San Jose, CA), with D-medium containing EGF in the bottom chamber. After $24 \mathrm{hr}$ at $37^{\circ} \mathrm{C}$, the cells on the top side were removed by scraping, and the invaded cells were fixed in methanol at $-20^{\circ} \mathrm{C}$ and visualized using the DiffQuik stain (Dade Behring, Deerfield, IL). Live images were taken under 10X magnification for counting of cells that invaded through the Matrigel. The experiments were done in triplicates and data were analyzed using the Student's $t$ test, for which $\mathrm{P}<0.05$ was considered significant. For the wound healing assay, the MCF10A-derived cells were grown to $90 \%$ confluence in growth factor deprived D3 medium $[24,69]$. A wound was made in the middle of culture dish containing near-confluent cells and the cells were stimulated with EGF containing D medium. Cells were photographed at $0 \mathrm{hr}$, before adding $\mathrm{D}$ medium and at 5 and $12 \mathrm{hr}$, after stimulating with D medium. Cells were photographed using a light microscope (4X).

\section{Immunofluorescence and Matrigel assays}

Immunofluorescence (IF) and Matrigel assays were performed as described $[24,69]$. Briefly, cells were plated in chamber slides. Cells were fixed in $4 \%$ formaldehyde, permeabilized with $0.5 \%$ Triton X-100 for $5 \mathrm{~min}$, and immunostained with anti-E-cadherin, anti-fibronectin, and anti-vimentin antibodies followed by staining with Alexa Fluor 488- and Alexa Fluor 594-conjugated secondary antibodies (Molecular Probes Inc. Eugene, OR) as required. The slides were mounted with Vectashield mounting medium containing 4',6-diamidino-2-phenylindole (DAPI) (Vector Laboratories). After staining, the cells were photographed (40X) using a Nikon Eclipse 80i confocal microscope. To perform Matrigel assays, cells were plated in 2\% Matrigel in a chamber slide on top of a polymerized layer of $100 \%$ Matrigel. The cultures were fed every 3 days. Phase-contrast images were obtained under 10X magnification. For immunofluorescence analyses, the cultures were fixed in $4 \%$ paraformaldehyde on day 12 , permeabilized with $0.5 \%$ Triton X-100 for $5 \mathrm{~min}$, and stained with anti-E-cadherin or anti- $\alpha 6$ integrin primary antibodies followed by Alexa Fluor 488conjugated secondary antibodies (Molecular Probes). Nuclei were stained with Topro-3 and slides were mounted with Vectashield mounting medium (Vector Laboratories). Images were acquired with a Nikon Eclipse 80i confocal microscope.

\section{Additional material}

Additional file 1 Supplementary data. The additional file contains Figure legends and Figures S1-S6.

\section{Competing interests}

The authors declare that they have no competing interests.

\section{Authors' contributions}

GPD conceived, coordinated the study, interpreted data and wrote the manuscript. AKY, AAS, MD, PVB and RS performed all the experiments, and helped in interpretation of the data and the preparation of the manuscript. All authors read and approved the final manuscript.

\section{Acknowledgements}

This work was supported in part by grant RO1 CA094150 from the National Cancer Institute, National Institutes of Health (GPD). MD gratefully acknowledges support from the Breast and Ovarian Research Program of the NorthShore University HealthSystem, Evanston, IL.

\section{Author Details}

1Department of Medicine, NorthShore University HealthSystem Research Institute, Evanston, IL 60201, USA, 2Dr. B.R Ambedkar Centre for Biomedical Research, University of Delhi Delhi-110007, India and ${ }^{3}$ Department of Surgery, Cardiovascular, University of Pennsylvania, PA 19036, USA

Received: 2 March 2010 Accepted: 22 June 2010

Published: 22 June 2010

\section{References}

1. Schwartz YB, Pirrotta V: Polycomb silencing mechanisms and the management of genomic programmes. Nat Rev Genet 2007, 8:9-22. 
2. Simon JA, Kingston RE: Mechanisms of polycomb gene silencing: knowns and unknowns. Nat Rev Mol Cell Biol 2009, 10:697-708.

3. Sparmann A, van Lohuizen M: Polycomb silencers control cell fate, development and cancer. Nat Rev Cancer 2006, 6:846-856.

4. Martinez AM, Cavalli G: The role of polycomb group proteins in cell cycle regulation during development. Cell Cycle 2006, 5:1189-1197.

5. Haupt Y, Alexander WS, Barri G, Klinken SP, Adams JM: Novel zinc finger gene implicated as myc collaborator by retrovirally accelerated lymphomagenesis in E mu-myc transgenic mice. Cell 1991, 65:753-763.

6. van Lohuizen M, Verbeek S, Scheijen B, Wientjens E, van der Gulden H, Berns A: Identification of cooperating oncogenes in E mu-myc transgenic mice by provirus tagging. Cell 1991, 65:737-752.

7. Bea S, Tort F, Pinyol M, Puig X, Hernandez L, Hernandez S, Fernandez PL, van Lohuizen M, Colomer D, Campo E: BMI-1 gene amplification and overexpression in hematological malignancies occur mainly in mantle cell lymphomas. Cancer Res 2001, 61:2409-2412.

8. van Kemenade FJ, Raaphorst FM, Blokzijl T, Fieret E, Hamer KM, Satijn DP, Otte AP, Meijer CJ: Coexpression of BMI-1 and EZH2 polycomb-group proteins is associated with cycling cells and degree of malignancy in Bcell non-Hodgkin lymphoma. Blood 2001, 97:3896-3901.

9. Sawa M, Yamamoto K, Yokozawa T, Kiyoi H, Hishida A, Kajiguchi T, Seto M, Kohno A, Kitamura K, Itoh Y, et al:: BMI-1 is highly expressed in M0subtype acute myeloid leukemia. Int $\mathrm{J}$ Hematol 2005, 82:42-47.

10. Vonlanthen S, Heighway J, Altermatt HJ, Gugger M, Kappeler A, Borner MM, van Lohuizen M, Betticher DC: The bmi-1 oncoprotein is differentially expressed in non-small cell lung cancer and correlates with INK4A-ARF locus expression. Br J Cancer 2001, 84:1372-1376.

11. Kim JH, Yoon SY, Kim CN, Joo JH, Moon SK, Choe IS, Choe YK, Kim JW: The Bmi-1 oncoprotein is overexpressed in human colorectal cancer and correlates with the reduced p16INK4a/p14ARF proteins. Cancer Lett 2004, 203:217-224.

12. Glinsky GV, Berezovska O, Glinskii AB: Microarray analysis identifies a death-from-cancer signature predicting therapy failure in patients with multiple types of cancer. J Clin Invest 2005, 115:1503-1521.

13. Kim JH, Yoon SY, Jeong SH, Kim SY, Moon SK, Joo JH, Lee Y, Choe IS, Kim $\mathrm{JW}$ : Overexpression of Bmi-1 oncoprotein correlates with axillary lymph node metastases in invasive ductal breast cancer. Breast 2004, 13:383-388

14. Kang MK, Kim RH, Kim SJ, Yip FK, Shin KH, Dimri GP, Christensen R, Han T, Park NH: Elevated Bmi-1 expression is associated with dysplastic cell transformation during oral carcinogenesis and is required for cancer cell replication and survival. Br J Cancer 2007, 96:126-133.

15. Song LB, Zeng MS, Liao WT, Zhang L, Mo HY, Liu WL, Shao JY, Wu QL, Li $\mathrm{MZ}$, Xia YF, et al.: Bmi-1 is a novel molecular marker of nasopharyngeal carcinoma progression and immortalizes primary human nasopharyngeal epithelial cells. Cancer Res 2006, 66:6225-6232.

16. Lessard J, Sauvageau G: Bmi-1 determines the proliferative capacity of normal and leukaemic stem cells. Nature 2003, 423:255-260.

17. Leung C, Lingbeek M, Shakhova O, Liu J, Tanger E, Saremaslani P, Van Lohuizen M, Marino S: Bmi1 is essential for cerebellar development and is overexpressed in human medulloblastomas. Nature 2004, 428:337-341.

18. Liu S, Dontu G, Mantle ID, Patel S, Ahn NS, Jackson KW, Suri P, Wicha MS: Hedgehog signaling and Bmi-1 regulate self-renewal of normal and malignant human mammary stem cells. Cancer Res 2006, 66:6063-6071.

19. Molofsky AV, He S, Bydon M, Morrison SJ, Pardal R: Bmi-1 promotes neural stem cell self-renewal and neural development but not mouse growth and survival by repressing the $\mathrm{p} 16 \mathrm{Ink} 4 \mathrm{a}$ and $\mathrm{p} 19 \mathrm{Arf}$ senescence pathways. Genes Dev 2005, 19:1432-1437.

20. Molofsky AV, Pardal R, Iwashita T, Park IK, Clarke MF, Morrison SJ: Bmi-1 dependence distinguishes neural stem cell self-renewal from progenitor proliferation. Nature 2003, 425:962-967.

21. Sangiorgi $E$, Capecchi MR: Bmi1 is expressed in vivo in intestinal stem cells. Nat Genet 2008

22. Glinsky GV: Death-from-cancer signatures and stem cell contribution to metastatic cancer. Cell Cycle 2005, 4:1171-1175.

23. Shimono Y, Zabala M, Cho RW, Lobo N, Dalerba P, Qian D, Diehn M, Liu H, Panula SP, Chiao E, et al: Downregulation of miRNA-200c links breast cancer stem cells with normal stem cells. Cell 2009, 138:592-603.

24. Datta S, Hoenerhoff MJ, Bommi P, Sainger R, Guo WJ, Dimri M, Band H, Band V, Green JE, Dimri GP: Bmi-1 cooperates with H-Ras to transform human mammary epithelial cells via dysregulation of multiple growthregulatory pathways. Cancer Res 2007, 67:10286-10295.

25. Hoenerhoff MJ, Chu I, Barkan D, Liu ZY, Datta S, Dimri GP, Green JE: BMI1 cooperates with H-RAS to induce an aggressive breast cancer phenotype with brain metastases. Oncogene 2009, 28:3022-3032.

26. Cao R, Tsukada $Y$, Zhang $Y$ : Role of Bmi-1 and Ring $1 A$ in $\mathrm{H} 2 \mathrm{~A}$ ubiquitylation and Hox gene silencing. Mol Cell 2005, 20:845-854.

27. Cao R, Wang L, Wang H, Xia L, Erdjument-Bromage H, Tempst P, Jones RS, Zhang Y: Role of histone $\mathrm{H} 3$ lysine 27 methylation in Polycomb-group silencing. Science 2002, 298:1039-1043.

28. Cao R, Zhang Y: SUZ12 is required for both the histone methyltransferase activity and the silencing function of the EED-EZH2 complex. Mol Cell 2004, 15:57-67.

29. Wang $H$, Wang $L$, Erdjument-Bromage $H$, Vidal $M$, Tempst $P$, Jones RS, Zhang Y: Role of histone H2A ubiquitination in Polycomb silencing. Nature 2004, 431:873-878.

30. Buchwald G, van der Stoop P, Weichenrieder O, Perrakis A, van Lohuizen M, Sixma TK: Structure and E3-ligase activity of the Ring-Ring complex of polycomb proteins Bmi1 and Ring1b. Embo J 2006, 25:2465-2474

31. Li Z, Cao R, Wang M, Myers MP, Zhang Y, Xu RM: Structure of a Bmi-1Ring1B polycomb group ubiquitin ligase complex. J Biol Chem 2006, 281:20643-20649

32. Alkema MJ, Wiegant J, Raap AK, Berns A, van Lohuizen M: Characterization and chromosomal localization of the human protooncogene BMI-1. Hum Mol Genet 1993, 2:1597-1603.

33. Cohen KJ, Hanna JS, Prescott JE, Dang CV: Transformation by the Bmi-1 oncoprotein correlates with its subnuclear localization but not its transcriptional suppression activity. Mol Cell Biol 1996, 16:5527-5535.

34. Dimri GP, Martinez JL, Jacobs JJ, Keblusek P, Itahana K, Van Lohuizen M, Campisi J, Wazer DE, Band V: The Bmi-1 oncogene induces telomerase activity and immortalizes human mammary epithelial cells. Cancer Res 2002, 62:4736-4745.

35. Itahana K, Zou Y, Itahana Y, Martinez JL, Beausejour C, Jacobs JJ, Van Lohuizen M, Band V, Campisi J, Dimri GP: Control of the replicative life span of human fibroblasts by 16 and the polycomb protein Bmi- 1 . Mol Cell Biol 2003, 23:389-401.

36. Rechsteiner M, Rogers SW: PEST sequences and regulation by proteolysis. Trends Biochem Sci 1996, 21:267-271.

37. Barnes JA, Gomes AV: Proteolytic signals in the primary structure of annexins. Mol Cell Biochem 2002, 231:1-7.

38. Gregory MA, Hann SR: c-Myc proteolysis by the ubiquitin-proteasome pathway: stabilization of c-Myc in Burkitt's lymphoma cells. Mol Cell Biol 2000, 20:2423-2435.

39. Lang V, Janzen J, Fischer GZ, Soneji Y, Beinke S, Salmeron A, Allen H, Hay RT, Ben-Neriah Y, Ley SC: betaTrCP-mediated proteolysis of NF-kappaB1 p105 requires phosphorylation of p105 serines 927 and 932 . Mol Cell Biol 2003, 23:402-413.

40. Mackichan ML, Logeat F, Israel A: Phosphorylation of p105 PEST sequence via a redox-insensitive pathway up-regulates processing of p50 NF-kappaB. J Biol Chem 1996, 271:6084-6091.

41. Medintz I, Wang X, Hradek T, Michels CA: A PEST-like sequence in the Nterminal cytoplasmic domain of Saccharomyces maltose permease is required for glucose-induced proteolysis and rapid inactivation of transport activity. Biochemistry 2000, 39:4518-4526.

42. Salmeron A, Janzen J, Soneji Y, Bump N, Kamens J, Allen H, Ley SC: Direct phosphorylation of NF-kappaB1 p105 by the IkappaB kinase complex on serine 927 is essential for signal-induced p105 proteolysis. J Biol Chem 2001, 276:22215-22222.

43. Shumway SD, Maki M, Miyamoto S: The PEST domain of IkappaBalpha is necessary and sufficient for in vitro degradation by mu-calpain. $J$ Biol Chem 1999, 274:30874-30881.

44. Wang N, Chen W, Linsel-Nitschke P, Martinez LO, Agerholm-Larsen B, Silver DL, Tall AR: A PEST sequence in ABCA1 regulates degradation by calpain protease and stabilization of ABCA1 by apoA-I. J Clin Invest 2003, 111:99-107.

45. Guo WJ, Zeng MS, Yadav A, Song LB, Guo BH, Band V, Dimri GP: Mel-18 acts as a tumor suppressor by repressing Bmi-1 expression and downregulating Akt activity in breast cancer cells. Cancer Res 2007, 67:5083-5089.

46. Dimri GP, Lee X, Basile G, Acosta M, Scott G, Roskelley C, Medrano EE, Linskens M, Rubelj I, Pereira-Smith O, et al.: A biomarker that identifies 
senescent human cells in culture and in aging skin in vivo. Proc Nat/ Acad Sci USA 1995, 92:9363-9367.

47. Guo WJ, Datta S, Band V, Dimri GP: Mel-18, a polycomb group protein, regulates cell proliferation and senescence via transcriptional repression of Bmi-1 and c-Myc oncoproteins. Mol Biol Cell 2007, 18:536-546.

48. Nowak K, Kerl K, Fehr D, Kramps C, Gessner C, Killmer K, Samans B, Berwanger B, Christiansen H, Lutz W: BMI1 is a target gene of E2F-1 and is strongly expressed in primary neuroblastomas. Nucleic Acids Res 2006, 34:1745-1754.

49. Alkema MJ, Jacobs $\mathrm{H}$, van Lohuizen M, Berns A: Pertubation of B and T cell development and predisposition to lymphomagenesis in Emu Bmi1 transgenic mice require the Bmi1 RING finger. Oncogene 1997, 15:899-910.

50. Fuchs SY, Spiegelman VS, Kumar KG: The many faces of beta-TrCP E3 ubiquitin ligases: reflections in the magic mirror of cancer. Oncogene 2004, 23:2028-2036.

51. Busino L, Donzelli M, Chiesa M, Guardavaccaro D, Ganoth D, Dorrello NV Hershko A, Pagano M, Draetta GF: Degradation of Cdc25A by beta-TrCP during $S$ phase and in response to DNA damage. Nature 2003, 426:87-91.

52. Jin J, Shirogane T, Xu L, Nalepa G, Qin J, Elledge SJ, Harper JW: SCFbetaTRCP links Chk1 signaling to degradation of the Cdc25A protein phosphatase. Genes Dev 2003, 17:3062-3074.

53. Ray D, Terao Y, Nimbalkar D, Chu LH, Donzelli M, Tsutsui T, Zou X, Ghosh AK, Varga J, Draetta GF, Kiyokawa H: Transforming growth factor beta facilitates beta-TrCP-mediated degradation of Cdc25A in a Smad3dependent manner. Mol Cell Biol 2005, 25:3338-3347.

54. Bhatia N, Thiyagarajan S, Elcheva I, Saleem M, Dlugosz A, Mukhtar H, Spiegelman VS: Gli2 is targeted for ubiquitination and degradation by beta-TrCP ubiquitin ligase. J Biol Chem 2006, 281:19320-19326.

55. Jiang J: Regulation of Hh/Gli signaling by dual ubiquitin pathways. Cell Cycle 2006, 5:2457-2463

56. Ding Q, He X, Hsu JM, Xia W, Chen CT, Li LY, Lee DF, Liu JC, Zhong Q, Wang $X$, Hung MC: Degradation of Mcl-1 by beta-TrCP mediates glycogen synthase kinase 3-induced tumor suppression and chemosensitization. Mol Cell Biol 2007, 27:4006-4017.

57. Dorrello NV, Peschiaroli A, Guardavaccaro D, Colburn NH, Sherman NE, Pagano M: S6K1- and betaTRCP-mediated degradation of PDCD4 promotes protein translation and cell growth. Science 2006, 314:467-471.

58. Thiery JP, Acloque H, Huang RY, Nieto MA: Epithelial-mesenchymal transitions in development and disease. Cell 2009, 139:871-890.

59. Cao Q, Yu J, Dhanasekaran SM, Kim JH, Mani RS, Tomlins SA, Mehra R, Laxman B, Cao X, Yu J, et al:: Repression of E-cadherin by the polycomb group protein EZH2 in cancer. Oncogene 2008, 27:7274-7284.

60. Herranz N, Pasini D, Diaz VM, Franci C, Gutierrez A, Dave N, Escriva M, Hernandez-Munoz I, Di Croce L, Helin K, et al:: Polycomb complex 2 is required for E-cadherin repression by the Snail1 transcription factor. Mol Cell Biol 2008, 28:4772-4781.

61. Song LB, Li J, Liao WT, Feng Y, Yu CP, Hu LJ, Kong QL, Xu LH, Zhang X, Liu $W L$, et al: The polycomb group protein Bmi-1 represses the tumor suppressor PTEN and induces epithelial-mesenchymal transition in human nasopharyngeal epithelial cells. J Clin Invest 2009, 119:3626-3636

62. Fan C, He L, Kapoor A, Rybak AP, De Melo J, Cutz JC, Tang D: PTEN inhibits BMI1 function independently of its phosphatase activity. Mol Cancer 2009, 8:98.

63. Chatoo W, Abdouh M, David J, Champagne MP, Ferreira J, Rodier F, Bernier $\mathrm{G}$ : The polycomb group gene Bmi1 regulates antioxidant defenses in neurons by repressing p53 pro-oxidant activity. J Neurosci 2009, 29:529-542.

64. Dimri GP: The search for biomarkers of aging: next stop INK4a/ARF locus. Sci Aging Knowledge Environ 2004, 2004:pe40.

65. Janzen V, Forkert R, Fleming HE, Saito Y, Waring MT, Dombkowski DM, Cheng T, DePinho RA, Sharpless NE, Scadden DT: Stem-cell ageing modified by the cyclin-dependent kinase inhibitor p16INK4a. Nature 2006, 443:421-426.

66. Kim WY, Sharpless NE: The regulation of INK4/ARF in cancer and aging Cell 2006, 127:265-275.
67. Krishnamurthy J, Ramsey MR, Ligon KL, Torrice C, Koh A, Bonner-Weir S, Sharpless NE: p16INK4a induces an age-dependent decline in islet regenerative potential. Nature 2006, 443:453-457.

68. Molofsky AV, Slutsky SG, Joseph NM, He S, Pardal R, Krishnamurthy J, Sharpless NE, Morrison SJ: Increasing p16INK4a expression decreases forebrain progenitors and neurogenesis during ageing. Nature 2006, 443:448-452.

69. Dimri M, Naramura M, Duan L, Chen J, Ortega-Cava C, Chen G, Goswami R, Fernandes N, Gao Q, Dimri GP, et al: Modeling breast cancer-associated c-Src and EGFR overexpression in human MECs: c-Src and EGFR cooperatively promote aberrant three-dimensional acinar structure and invasive behavior. Cancer Res 2007, 67:4164-4172.

70. Dimri GP, Itahana K, Acosta M, Campisi J: Regulation of a senescence checkpoint response by the E2F1 transcription factor and p14(ARF) tumor suppressor. Mol Cell Biol 2000, 20:273-285.

71. Dimri M, Bommi P, Sahasrabuddhe AA, Khandekar JD, Dimri GP: Dietary omega-3 polyunsaturated fatty acids suppress expression of EZH2 in breast cancer cells. Carcinogenesis 2009, 31:489-95.

doi: 10.1186/1476-4598-9-158

Cite this article as: Yadav et al, Deletion analysis of BMI1 oncoprotein identifies its negative regulatory domain Molecular Cancer 2010, 9:158

\section{Submit your next manuscript to BioMed Centra and take full advantage of:}

- Convenient online submission

- Thorough peer review

- No space constraints or color figure charges

- Immediate publication on acceptance

- Inclusion in PubMed, CAS, Scopus and Google Scholar

- Research which is freely available for redistribution
C Biomed Central 